\title{
The Need for Pedagogical Qualifications for Teaching Cardiology to Undergraduate Students
}

\author{
Waldomiro Carlos Manfroi, Carmen Lúcia Bezerra Machado, Ana Maria Petersen, Maria Júlia P. Spina \\ Porto Alegre, RS - Brazil
}

\begin{abstract}
Objective - To report a training program in cardiology emphasizing changes in its pedagogical practice. These changes were put into practice by someteachers at the Medical School of Porto Alegre of the University of Rio Grande do Sul (FAMED/UFRGS) aiming to makefaculty and studentactivities more dynamic and to promote more efficacious learning. The training program is directed at $5^{\text {th }}$ semester medical students and aims at a behavioral change in teachers and students to promotemore interaction, to favor exchanges, and to make the teaching-learning process easier, always maintaining the patient in the center of the medical activity.
\end{abstract}

Methods - The program emphasizes the definition of general and specific objectives for each activity to be developed by the students, with training in the area of admission to the cardiology service, with special emphasis on behavioral change in the cognitive, motor, affective, and attitudinal areas. Knowledge was developed by means of interactive seminars with initial and final assessment tests to identify students' and teachers' performance. The students were evaluated in an immediate, continuous, and progressive way in their daily activities and through comparison of the results of 2 tests, one applied at the beginning of the training and the other at its end. These 2 tests contained the same questions.

Results - We systematically assessed 560 students over 4 years. The mean grades of the tests performed prior to and after the 244 seminars were $7.38 \pm 1.66$ and $9.17 \pm$ 0.82 , respectively $(p<0.0001)$. For the tests applied at the beginning and at the end of the training, the mean grades were $5.61 \pm 1.61$ and $9.37 \pm 0.90$, respectively $(p<0.0001)$.

Conclusion - The program proved to be efficient both for the students' learning and for assessing their performance in a systematic and objective way.

Key words: cardiology, teaching, pedagogical references

Hospital de Clínicas de Porto Alegre - FAMED/UFRGS

Mailing address: Waldomiro Carlos Manfroi - Rua Alcides Gonzaga, 330 - 90480020 - Porto Alegre, RS, Brazil - E-mail: manfroi@orion.ufrgs.br or wmanfroi@ terra.com.br

English version by Stela Maris C. e Gandour
Medical education has become more and more demanding and complex due to the multiplicity of investigative and therapeutical innovations introduced into the services dedicated to teaching. Of these, we can emphasize the incorporation of new technologies to identify and solve problems, and the extension of medical residency programs and postgraduate courses with their research projects. These new fields of activity have broadened the areas of teachers' activities and the horizon of possibilities for students.

In regard to undergraduate education, how has it been performed? Will the simple incorporation of the student into the complex system of multiple investigative and therapeutical focuses provide the best conditions for them to acquire knowledge, skills, behavior, and ethical postures?

The following Brazilian saying is very popular: "the one who learns, is the one who does, and only the one who knows, does". To assume that a student learned something just because he was present during the time a specific task was performed in a given health service may represent a false assumption of what a student really learned and what he really knows how to do. Learning cannot be seen just as the result of rote memorization.

Until the mid 1960s, tests were used to assess students' knowledge (stored information), but other elements cur-rently considered substantial, such as projects, programs, curriculum, teacher's performance, and even the conditions and resources provided by educational institutions, were not valued then ${ }^{1}$.

Very slowly, however, other proposals for evaluation have appeared and have been used so far. These proposals have changed the emphasis given to the role played by evaluation in the learning-teaching process. Since then, evaluation began to be seen as a learning opportunity, for both students and teachers. These new assumptions have revealed the need for a program, for sharing the objectives to be reached, and for defining instruments and criteria that allow the recognition and evaluation, with the maximum safety possible, of the progression of the students, both in regard to the intellectual construction of knowledge or the development of skills and the mastering of practical techniques involved in medical practice.

Educational programs should consider broader as- 
pects, not just focusing on one set of contents and another set of evaluating questions. This way, other elements, such as the diagnosis of social needs, the formulation of objectives, the selection of contents in the program, the teaching techniques, and the evaluation processes, have appeared in the teaching programs.

Therefore, we understand that the teaching-learning process should comprise scientific discipline so that the objectives can clearly express what the students should accomplish and the conditions offered during their tenure. This should be the guiding approach to any type of evaluation. Quoting the Cheshire-Cat in Lewis Carroll's Alice's Adventures in Wonderland:

"...Come, it's pleased so far," thought Alice, and she went on. "Would you tell me, please, which way I ought to go from here?"

"That depends a good deal on where you want to get to," said the Cat.

"I don't much care where-" said Alice.

“Then it doesn't matter which way you go," said the Cat ${ }^{2}$.

In our training program, evaluation is no longer understood as an instrument of analysis of the students' performance, but a learning opportunity for both students and teachers. Evaluation serves as a way to identify the possible difficulties and the relevance of the program, and even to rethink the teachers' performance ${ }^{3}$.

This study aims to report a new modality for teaching cardiology, which was introduced for undergraduate students in our service, and also to report the results obtained during the first 7 years of its application and 4 years of follow-up.

\section{Methods}

In a first phase, we tried to identify the conditions provided by the Cardiology Service to achieve the objectives of teaching the disciplines defined by the Department of Internal Medicine of the Medical School of the Universidade Federal do Rio Grande do Sul.

Once the study was concluded in 1992, we implemented a new model of teaching through which we could calibrate the conditions of the Service with the objectives of the discipline. New techniques of theoretical teaching were then introduced with a better systematization for teaching skills and behaviors to students undergoing curriculum training in their undergraduate education. The project was not part of a curriculum change or of a new proposal for medical school education. The training sessions lasted 4 weeks, in which 14 students divided into 2 groups of 7 each participated, and 6 teachers alternated with the activities at each change of students. The evaluation system was especially emphasized so that we could follow up the performance of the students, teachers, and the service in a permanent, continuous, and progressive way. Superposition of the teachers' activities in their multiple tasks in the Service was avoided. For this, the levels of knowledge, skills, behavior, and attitudes that should be the objectives of undergraduate education were defined, as also was the approach that should guide the teachers' actions in regard to the students ${ }^{4,5}$.
In the following phase, the objectives regarding knowledge, skills, behavior, and attitudes that the students should acquire by the end of the training program were defined and were as follows: to adequately collect data of anamnesis and physical examination; to explain diagnostic hypotheses or lists of problems and to interpret laboratory test results; to accurately and clearly report the patients' daily evolution in the patients' records, stressing the relevant facts regarding the clinical findings and the recommended therapeutical measures; to thoroughly analyze and consider the etiopathogeny of the major diseases of the cardiovascular system, the pharmacokinetic actions, pharmacodynamics, dosages, and side effects of the prescribed drugs, and the clinical manifestations of the prevalent cardiovascular diseases; to adopt primary and secondary preventive measures, considering the etiological agents and the risk factors involved in the genesis and progression of cardiovascular diseases; to recognize emergency and urgent situations, indicating diagnostic procedures and pertinent therapeutic measures; to identify rhythm, heart rate, indicators of cavity hypertrophy, ischemia, lesion, necrosis, and bundle-branch block in the conventional electrocardiogram; to identify, through conventional radiography, the enlargement of the cardiac cavities and signs of right and left heart failure; to develop a proper ethical approach in relationships with patients, peers, and the work team; to propose changes in the program to improve the teaching and evaluation processes.

In regard to the development of the motor area, special emphasis was given to the tutorial role played by the teacher when performing the patient's physical examination, analyzing laboratory test results, and discussing topics in small groups.

The development of cognitive skills was provided by the following activities: presentation of 7 seminars (ischemic syndromes, myocardial infarction, pathophysiology and diagnosis of heart failure, treatment of heart failure, systemic arterial hypertension, valvular heart diseases, primary cardiomyopathies), theoretical classes on electrocardiography, and assignment of tasks that stimulate study in an independent way or in small groups, such as reading, using a microcomputer and video, accessing the Internet, and elaborating on patients' reports; clinical meetings with the teachers, residents, and postgraduate students; and journal club. These activities are listed in a previously defined schedule in appendix 1 .

The seminars were the most important tools for developing cognitive skills, and they were presented in a way that promoted integration between the state-of-the-art knowledge and the development of medical skills and management.

On the first day of training, the students were introduced to the program and received a copy of the proposed activities, the modules of the 7 meetings inclusive. The dates and places of these activities, their specific objectives, their program, their educational strategy, the evaluation system, and the bibliographic references were specified there. At the beginning of each seminar, the students answered 10 questions (initial test) related to the objectives and the training program. Then 4 students were randomly chosen, and they had 15 minutes (each) to deliver an exposé of the seminar 


\begin{tabular}{|c|c|c|c|c|c|}
\hline \multicolumn{6}{|c|}{$\begin{array}{c}\text { Appedix } 1 \\
\text { Schedule of the activities }\end{array}$} \\
\hline & Monday & Tuesday & Wednesday & Thursday & Fridey \\
\hline 7:30 - 8:00 A.M. & Patients' evolution & Patients' evolution & Journal club & Patients' evolution & \\
\hline 8:00 - 8:30 A.M. & Patients' evolution & Patients' evolution & Patients' evolution & Patients' evolution & $\begin{array}{l}\text { Seminar with the teacher } \\
\text { (8:00 - 9:30 A.M.) }\end{array}$ \\
\hline 8:30 - 10:20 A.M. & $\begin{array}{l}\text { Evaluation / discussion of } \\
\text { cases with the professor }\end{array}$ & $\begin{array}{l}\text { Evaluation / discussion of } \\
\text { cases with the professor }\end{array}$ & $\begin{array}{l}\text { Evaluation / discussion of } \\
\text { cases with the professor }\end{array}$ & $\begin{array}{l}\text { Evaluation / discussion of } \\
\text { cases with the professor }\end{array}$ & $\begin{array}{l}\text { Patients'evolution } \\
\text { Evaluation / discussion of } \\
\text { cases with the professor } \\
(9: 30 \text { - 12:00 A.M. })\end{array}$ \\
\hline 10:30 - 12:00 A.N & M. Seminar with the teacher & ECG class & ECG class & $\begin{array}{l}\text { Discussion of clinical cases, } \\
\text { rated with the postgraduate c }\end{array}$ & ourse \\
\hline
\end{tabular}

topic, which was followed by a discussion involving the remaining students and teachers. At the end of the activity, the initial questions were answered once again (final test), according to already known models ${ }^{6}$. The modules of the 7 seminars were developed according to the same pattern, as exemplified in appendices 2 and 3 .

This way, the student could be assessed in an immediate, continuous, and progressive way encompassing all activities performed during the training. The teachers were responsible for the assessment in their areas of activity. Meetings with teachers of the different cardiology subspecialties were performed to promote a coordinated evaluation of each student. Medical skills and management were assessed by the teachers through systematic observation, in a daily follow-up of the students, in their activities with the patients, using a spreadsheet to assess performance, according to appendix 4 .

The parameters used were the quality of the anamneses and physical examinations, elaboration of diagnostic hypotheses, requisition and interpretation of laboratory examinations, therapeutical management, preventive mea-

\section{Apendix 2}

Seminar 1 - Ischemic syndromes

Date..............

Professor in charge:

Specific objectives: after attending the seminar under the supervision of a professor, the student should be able to: 1) describe the theories that try to interpret the genesis and progression of coronary atherosclerosis; 2) report the risk factors involved in the genesis and progression of coronary atherosclerosis, citing some studies that support the current knowledge; 3) describe the clinical forms of ischemic syndromes, characterizing the clinical findings of stable angina and its different forms; 4 ) describe the characteristics of the pain of angina pectoris, and the triggering, relieving, and aggravating factors of this clinical manifestation; 5) cite other disease that may be confused with angina pectoris; 6) cite the sequence of laborary investigation in ischemic syndromes (tredmill exercise test, echocardiography, myocardial scintigraphy, with the use of drugs, Holter monitoring, and coronary angiography); 7) to elaborate a therapeutical plan for each of the ischemic syndromes, describing the pharmacokinetics, pharmacodynamics, effects and side effects of the drugs used in their treatment, highlighting the nitrates, the beta-blockers, the calcium antagonists, the antiplatelet agents, the anticoagulants, and the measures of myocardial revascularization using bypass grafts or invasive hemodynamics. sures, quality of the patient's daily evolutions, knowledge shown in group discussions and in the reports provided to the teachers. Acquisition of knowledge during the training program was objectively assessed through initial and final tests performed on the occasion of the seminars and through the comparison of the results of 2 tests, one given at the beginning of the training and another at its end, comprising 20 multiple choice or discussion questions ${ }^{7-9}$.

Data were presented as media \pm standard deviation. The answers to all questions were analyzed using the Student $t$ test and Fisher test for paired data, and the significance level was previously defined as 5\%.

On the last day of training, in addition to the already cited test, the students answered, anonymously, a questionnaire with objective multiple choice questions about their opinion about the teaching techniques used, the performance of the teachers in each specialty, and the conditions of the service ${ }^{10}$.

\section{Results}

We assessed 560 students divided into 40 groups in the first 4 years of the training program.

\section{Appendix 3 \\ Training program}

1) Pathogenesis of coronary atherosclerosis and its risk factors: major theories that try to explain the endothelial lesion, the formation and progression of the atheroma, and the participation of risk factors; 2) concept of myocardial ischemia and its pathophysiology: notions on flow supply, demand, and reduction; 3) clinical characteristics of myocardial ischemia: stable angina pectoris, unstable angina pectoris (of recent onset, with a change in character, angina decubitus, intermediate coronary syndrome, postinfarction angina, and the Prinzmetal variant); 4) concept of functional myocardial ischemic: causes and mechanisms; 5) silent myocardial ischemia - incidence, significance, and evaluation; 6) laboratory tests to support the diagnosis of myocardial ischemia and its risk stratification (exercise test, drugs, Holter monitoring, echocardiography, myocardial scintigraphy, coronary angiography). Which trests should be asked and when?; 7) drug treatment of ischemic syndromes: coronary vasodilators; beta-blockers; calcium channel blockers; antiplatelet agents; others. Pharmacokinectcs, pharmacodynamics, dosagens, and major side effects; 8) secondary prevention in ischemic syndromes; 9) treatment of myocardial ischemia using invasive hemodynamics; 10) treatment using myocardial revascularization surgery: when it is indicated. 


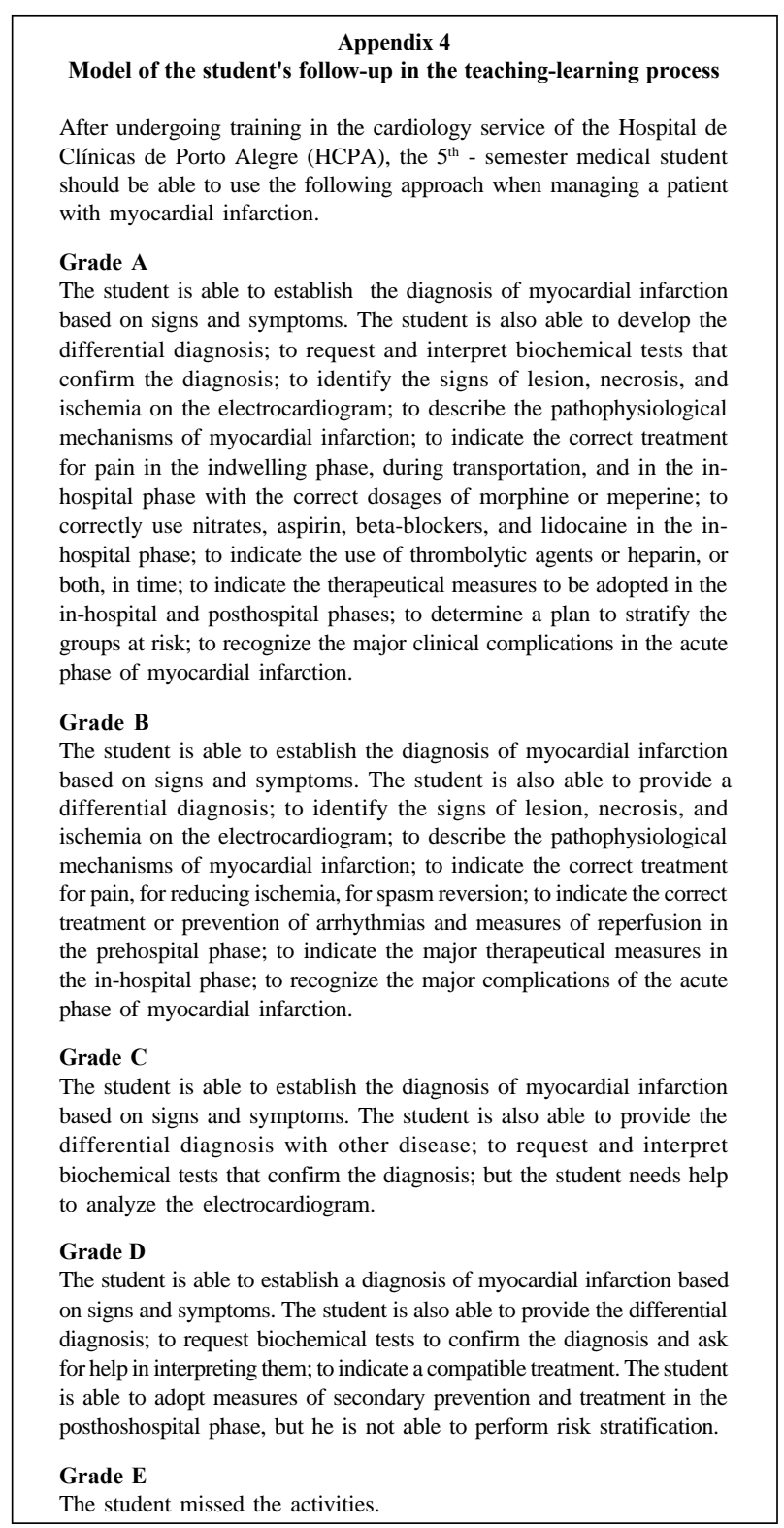

The mean grades on the tests applied at the beginning and at the end of the training were, respectively, $5.61 \pm 1.48$ and $9.17 \pm 0.82(p<0.0001)$, and the mean grades in the initial and final tests of the 244 seminars were, respectively, $7.38 \pm 1.66$ and $9.37 \pm 0.90(<0.0001)($ tab. I).

\section{Discussion}

Traditionally, the services dedicated to teaching cardiology use, as an educational strategy, a list of contents organized as programs of disciplines, which are delivered in magisterial classes for huge groups of students and followed by practical activities at the patient's bedside. The evaluation procedures, with rare exceptions, are based on aspects observed by the teachers, on the apparent interest of the student, attendance to activities, and the results of written tests. This practice of evaluation has been part of the

\begin{tabular}{|lccc|}
\hline \multicolumn{4}{|c|}{$\begin{array}{c}\text { Table I - Results of the tests given before and after the seminars } \\
\text { and of those given at the beginning and at the end of the training } \\
\text { program }\end{array}$} \\
\hline & Seminar tests & Training tests & $\mathrm{p}$ \\
\hline Pré-teste & $7.38 \pm 1.62$ & $5.61 \pm 1.48$ & $<0.0001$ \\
Pós-teste & $9.37 \pm 0.90$ & $9.17 \pm 0.82$ & $<0.0001$ \\
\hline
\end{tabular}

pedagogical procedures that have provided the formation of generations of professionals, who are dedicated to medical teaching, assistance, and research ${ }^{11}$.

However, multiple, new techniques have been introduced more and more for the diagnosis and treatment of cardiac diseases. All this progress that undoubtedly boosts medical science draws part of the teacher's attention away from the activities involving undergraduate education.

Simultaneously with the occurrence of advances in the medical area, the teaching concepts and learning also evolved in their pedagogical techniques. Acquisition of this new knowledge about the characteristics of the process of learning and of all mechanisms involved in the construction of knowledge does not allow us to remain immobilized in our actions regarding teaching conditions ${ }^{12}$.

The formation of a physician at the undergraduate or postgraduate level, or both, needs to be rethought as far as its pedagogical practice is concerned, because to accompany the development of science, the communications, and the results of research, among others, teachers require constant updating. This attention naturally implies a greater amount of time spent in updating knowledge, which, however, should not affect the amount of time dedicated to students.

So, we face a dilemma: how can a teacher incorporate these new requirements and be efficient in all his actions? The answer leads us to an unquestionable point: the teacher needs to review his pedagogical practice if he wants his teaching work to be successful. Therefore, it is currently unacceptable that a teacher does not correctly assess the developmental stage of his students. Identifying the level of knowledge and skills of the students at the beginning of the training is indispensable, so that one may verify whether they reached the objectives proposed by the end of training.

During the development of our study, we recognized that the level of cardiology knowledge among the students was distinct in the different groups, as were the level of interest and the expectations of each student. The necessity to consider this previous knowledge is inherent in the constructionist conception about gaining knowledge, because this activity cannot be carried out from scratch. Assimilating new knowledge and constructing meanings always involve the possibility of establishing contact, which will only occur based on something already known.

When the student has to learn something new, he always uses a series of concepts, conceptions, representations, and knowledge acquired from previous experiences, such as reading and interpretation instruments. These instruments will determine most of the selected information, 
how it will be organized, and the type of relations established between each piece ${ }^{6}$. Therefore, the first reading of any new knowledge content depends on the student's background.

Our training program was implemented based on a reformulation of the pedagogical practice aiming to help undergraduates become more self-confident and efficient in their learning process.

We could have followed several paths in this search. But we chose to define objectives and carefully emphasized planning teaching situations and selecting the contents, and, in particular, we renewed attention to the evaluation process. Therefore, the program is characterized by the development of individual or small-group works with a special emphasis on practical activities for acquiring medical skills and management.

The innovative objective of the program was the search for the integrated development of cognitive and motor skills and of medical management and attitudes, based on the principles of investigation, on continuing study, and on critical and creative sense ${ }^{13-15}$.

With this new approach, we observed, in an objective way, the students' achievements at different times of evaluation. It is worth noting that the students also assessed the training program, the teachers, the quality of the service, and the strategies used in the theoretical and practical teaching situations as positive.

The analysis of the tests given before the seminars showed that the students had undergone good preparation for the activity, considering that the mean grade prior to discussions was $7.38 \pm 1.62$, and after the seminar it was $9.37 \pm 0.9(\mathrm{p}<0.0001)$. One of the objectives of our program was to make students study independently, and this was achieved because the students arrived well prepared for the seminars. Certainly, this is a way to develop the habit of continuing study, based on self-evaluation. Comparing the mean grades obtained before and after the seminars, the efficacy of the technique is evident. From the point of view of global achievement in the cognitive area during the training, the results were identified by comparing the mean grades obtained on the tests performed at the beginning and at the end of the training program comprising the same 20 questions. In the latter, a significant enhancement in student's per-formance was also evident. The mean grades obtained in the tests given at the beginning and at the end of training were $5.61 \pm 1.48$ and $9.17 \pm 0.82$, respectively $(\mathrm{p}<0.0001)$.

Objectively, the training program has been reaching its goals with a very low failure index (4\%).

We do not intend to prove that this teaching model is better or more recommended than others, but it certainly considers teaching in a differentiated way. We can state, however, that the results considered positive here have been maintained unaltered in the different groups over 7 years.

We suggest that other training programs with the same characteristics should be implemented in other places, so we can perform comparative studies, and, if necessary, rethink our program.

Finally, we emphasize that we believe that several paths exist leading to an efficient result in teaching cardiology to undergraduates. However, we fear that, in the face of current technological development, the art of medicine may be lost. From our point of view, we can prevent this type of loss by implementing training programs with systematic student follow-up.

\section{References}

1. Bloom BJ, Krathwohl DR, Masia BB. Taxonomy of Educational Objectives. Porto Alegre: Globo, 1972.

2. Caroll L. Alice no País das Maravilhas. São Paulo: Cultrix, s/d.

3. Becker F. A Epistemologia do Professor. $7^{\text {a }}$ ed. Revisada. Petrópolis: Vozes, 1999.

4. Batista, NA, Silva, SHS. A função docente em medicina e a formação/educação permanente do professor. R Bras Educ Med 1998; 22: 31-6.

5. Borges DR, Stella RCR. Avaliação do ensino de medicina na Universidade de São Paulo. R Bras Educ Med 1999; 23: 11-5.

6. Coll C. O Construtivismo na Sala de Aula. São Paulo: Ática, 1999.

7. Dias CMS, Galliazi MC, Thomaz TCF. Significado da avaliação no processo ensino-aprendizagem. Educação 1996; 19: 117-34.

8. Gonçalves EL. Os objetivos da educação médica. R Bras Educ Med 1999; 23: 9-21.

9. Haydon R, Donelly M, Schwaartz R, et al. Use of standardized patients to identify deficits in student performance and curriculum effectiveness. Am J Surg 1994; 168: 57-65.
10. Hoole AJ, Kowlowitz V, Gaghie WC, et al. Using the objective structured clinical examination at the University of North Carolina Medical School. NCMJ 1987; 48: 463-7.

11. Nogueira HE. A educação médica e o país real. Médicos. HC/FMUSP 1998: $30-7$.

12. Piaget J, Inhelder B. Le rôle des opérations dans le dévelloppement de l'intelligence. Proc. $12^{\text {th }}$ Int Congre. Psychol 1948: 102-3.

13. Medeiros MF, Colla AL. Tecnologia da educação: ciência, técnica e os nexos entre teoria e prática determinados por racionalidades que orientam o uso do conhecimento. Tecnologia Educacional 1994; 22: 9-21.

14. Peixoto MAP, Silva RNMB. Estratégias de aprendizagem em alunos de medicina: pré-teste. R Bras Educ Med 1999; 23: 18-31.

15. Stillman P, Swanson D, Regan MB, et al. Assesment of clinical skills of residents utilizing standardized patients: a follow-up study and recommendations for application. Ann Intern Med 1991; 114: 393-401. 